\title{
DISCUSSION ON RESTORATION DESIGN OF LANDSCAPE SITE BASED ON 3D- TERRESTRIAL LASER SCANNING : A CASE STUDY OF QIWANG HALL IN SUMMER PALACE, BEIJING, CHINA
}

\author{
Zhang Long ${ }^{1, *}$, Wang Aoyi ${ }^{1}$ \\ ${ }^{1}$ Architecture school of Tianjin University, Tianjin 300072, China - (arcdragon, wang_aoyi)@163.com
}

KEY WORDS: 3D- terrestrial laser scanning, Heritage Conservation, the Summer Palace, Qiwang Hall, Restoration design

\begin{abstract}
:
In recent years, new technologies have been developed and applied in the field of heritage conservation, such as Three-dimensionalterrestrial laser scanning (TLS). The academia pays more attention to the heritages which remain relatively intact, but neglects those destroyed. Research on information collection and restoration of sites helps to better protect the damaged sites and deepen people's understanding of the value of heritage. This study will conduct a detailed survey of the status quo of the site, providing basic information for the protection of the site. At the same time, the existing archives and documents are excavated and sorted out, and the restoration research of Qiwang Hall is carried out on the basis of the site and archives, which can make up for the shortcomings of the previous research and provide a reference of methods for the relevant research.
\end{abstract}

\section{INTRODUCTION}

\subsection{General Instructions}

3D laser scanning technology is increasingly used in the field of heritage protection, such as the digitization of surveying, mapping, modeling and other data of cultural heritage buildings (Shao et al. 2019a). Chinese classical gardens imitate nature during construction, and the layout is flexible and free. Such as the royal gardens of the Qing Dynasty, they are located in natural landscapes, including various landscape elements and complex spaces. Traditional manual measurement is limited to large scale and complex garden environment. The survey records of the garden walls, ancient trees, garden paths, rockery remains, and architectural foundations are the basis for the restoration of the overall pattern of the landscape site. Therefore records of TLS point clouds, 3D models and fine twodimensional drawings are essential for the protection of cultural sites.

The Summer Palace is a masterpiece of Chinese traditional gardening art. It has unique historical, artistic and cultural values. It is also the most complete large-scale royal garden in China. It is a rare physical carrier for studying ancient Chinese gardening ideas and garden design methods. There are many "garden within a garden" sites in the Summer Palace, such as the site of Qiwang Hall as the junction of water and land transportation at the back of the longevity hill of the Summer Palace. The public's awareness of the value of the Summer Palace as a world cultural heritage is not enough, especially for the sites that exist in it. During the visit, we found that few tourists had any knowledge of the sites of the Summer Palace. The study on the restoration of the site is the basis of effective protection and exhibition, which is the necessary link to deepen the overall value cognition of the Summer Palace and to fully display the Summer Palace. At the same time, in addition to the archaeology of the site, the restoration study of the garden in the Royal Garden of the Qing Dynasty was supported by archives. We chose Qiwang Hall as an example of digital recording and restoration research.

\subsection{Previous research}

Around the 1960s, Zhang Jinqiu made a general study of the original landscape and landscaping experience of Qiwang Hall (School of Architecture, Tsinghua University, 2000). However, due to the limitation of research materials, there are some doubts about the title of buildings, the number of stories and the form of corridors. Jin Boling also analyzed the landscape art of the back hill of Longevity Hill in the Summer Palace but lacked accurate investigation and restoration studies of specific landscapes (Jin, 1984a). At the same time, due to the limitations of the conditions of the year, the predecessors only recorded and investigated the image pattern of the site during the research, leaving no digital files, and there were also omissions in the mapping and recording of the site components.

\section{STUDY SITE}

We chose Qiwang Hall as the study site. Qiwang Hall was built in 1750 and completed before 1754. It is a "garden within a garden" located on the northwest side of Longevity Hill in the Summer Palace (Figure 1). The garden's name, "Qiwang Hall", comes from one of the most important buildings in it. In order to distinguish between the architecture and garden, the garden will be called Qiwang Hall Garden in the process of writing. The Hall for Watching Cloud Rising is located across the river from Qiwang Hall Garden. They are closely related and cannot be studied independently. It is a brief stopover in the Emperor Qian Long's visit to the Qingyi Garden (pre-existence of the Summer Palace). It is also an important traffic node for the "water route" and "land route". It has very important research significance and value. Unfortunately, it was ruined with the fall of the Qing Dynasty. Due to the limitation of the current situation in the Guangxu Dynasty, it could not be rebuilt. At

\footnotetext{
* Corresponding author
} 


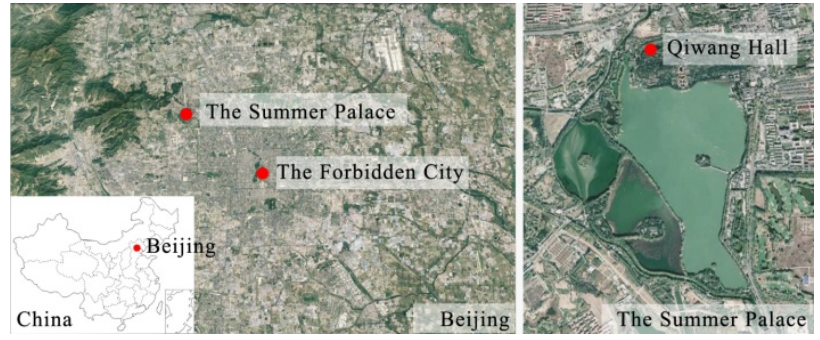

Figure 1. The location of Qiwang Hall

present, only historic sites remain in Qiwang Hall Garden(Figure 2) and the Hall for Watching Cloud Rising (Figure 3).

From the south bank of the north river in the summer palace, you can enter the Qiwang Hall Garden through the steps left on both sides of the gate. It can also reach the interior of the garden directly through the stacking stone culvert stairs inside the gate. There are four exits in the culvert, hidden in the rockery of the south side of Hanxiang Pavilion (a pavilion by the river in Qiwang Hall Garden). The overall topography is gradually rising from north to south so that even in the southern courtyard of the Qiwang Hall Garden, people can also look across the scenery in the north bank. The Qiwang Hall Garden consists of 6 buildings connected by a corridor. The whole garden is divided into three courtyards in the north, south, and west by the buildings and corridors. The northern boundary of the garden is a corridor connected with the southern wall. The east, west and south sides of the garden are surrounded by low-lying earth hills. The caves formed by stacked stones on the south side of the courtyard are one of the land entrances of the Qiwang Hall Garden. At the entrance to the "cave", a "curved path" is created, and the terrain in the park gradually decreases from south to north, making the entire garden hidden in the cascade of mountains and the environment is quiet. There are several ancient cypress trees in the west side courtyard. The winding road of rockery and the ancient cypress trees echo the horizontal inscribed board and couplets written by the emperor Qianlong at the gate of the river bank, reflecting the overall aesthetic interest of the garden. On the south-western part of the west side courtyard, there is a hole in the wall and a stone step below. It is another entrance to the Qiwang Hall Garden, which leads directly to the park.

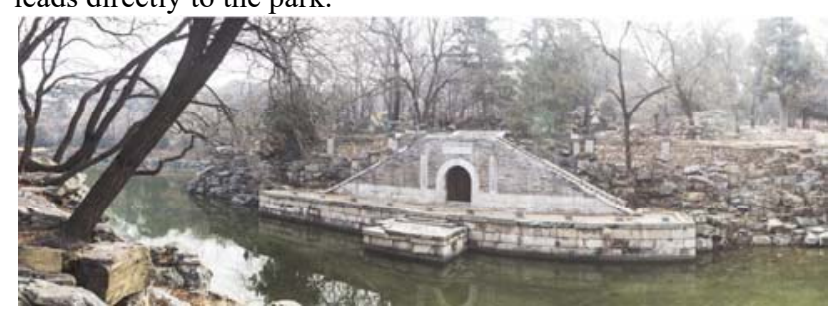

Figure.2 Current Situation of Qiwang Hall

On the other side of Qiwang Hall Garden, the Hall for Watching Cloud Rising is built on top of a rockery stack, which can be reached by stone steps on both sides of the east and west. It has no dock, and the north side is the outer boundary of the entire Summer Palace, with low accessibility. Therefore, it is speculated that it was originally created as a viewing place for Qiwang Hall on the other side of the river, rather than a place to visit. The remains of the path, apron, and paving bricks are still visible in the garden. There are two ancient cypress trees on either side of the main hall.

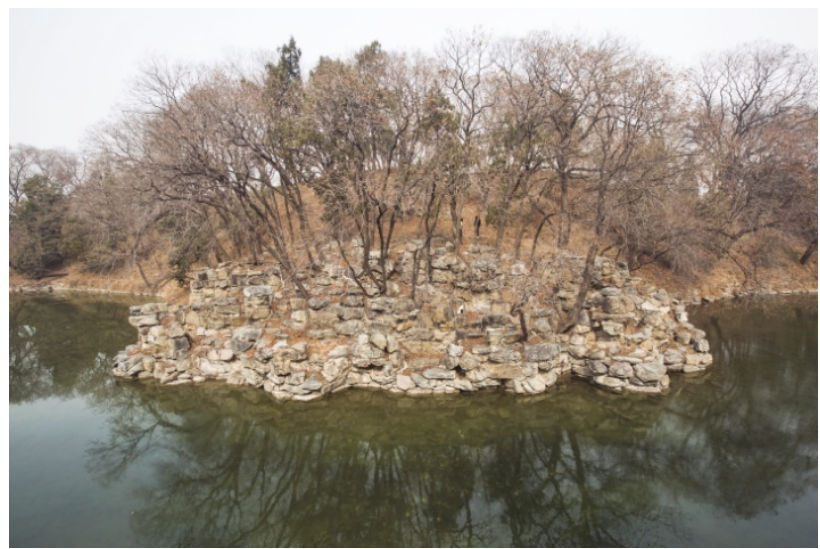

Figure 3. Current situation of the Hall for Watching Cloud Rising

\section{MATERIALS}

\subsection{Survey of the site}

After a hundred years of revolution, many sites of the imperial gardens of the Qing dynasty were left behind due to war damage, artificial demolition, improper maintenance, and other reasons. These sites are an integral part of our understanding of the integrity and authenticity of royal gardens. Early sites, such as the Tang and Song Dynasties (between about 600 and 1200 AD), can only be approximated by archaeological excavations (Wang, 2017). Little remains of them are preserved. The garden sites of the Qing Dynasty are closer to the present, and the base site layout was relatively well preserved, which provided a good foundation for the restoration work. Relatively speaking, the evidence for the restoration of garden sites in the Qing Dynasty is more abundant. Taking Qiwang Hall Garden as an example, we can get building information and landscape relic information such as stacked stones, plants and mountain-shaped water systems from the remains.

For example, we can judge the entire garden through the traces of the wall base outside the corridor, which further confirms that the space intention of the garden in the Imperial Garden in Qianlong period is inward-looking (Figure 4). Taking a pavilion in the Qiwang Hall Garden as an example, we can easily obtain the building's plane information due to the rich information retained in the site, such as the location of the wall (Figure 5).

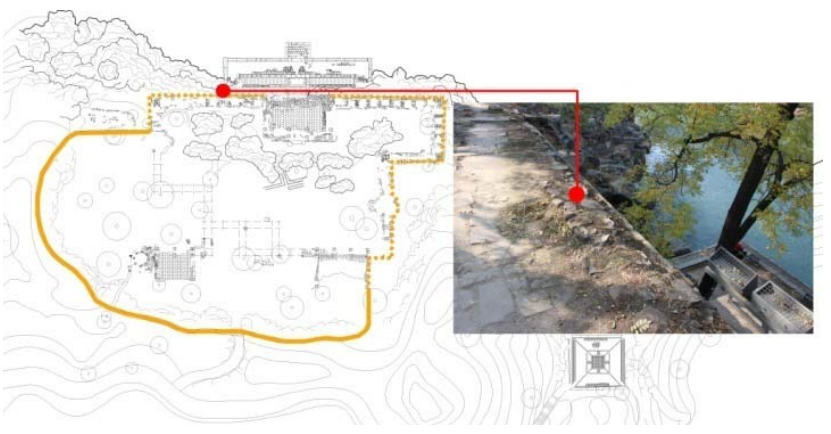

Figure 4. Traces of the wall of the Qiwang Hall Garden

At the same time, with the aid of TLS, the records of the stacked stones, ancient trees, and topography in the garden environment are the basis for the overall restoration study. Through these records, an environmental model is established 


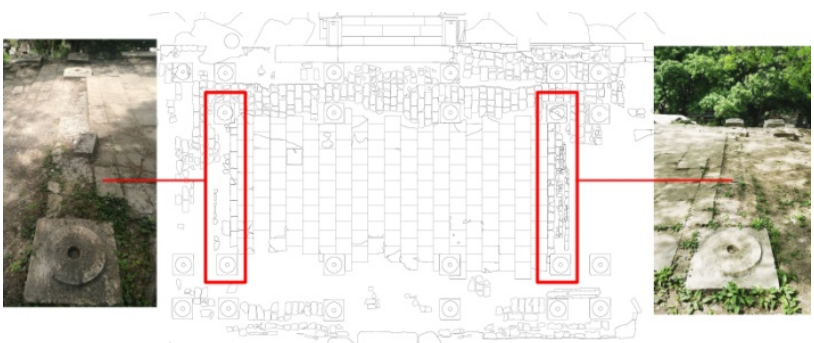

Figure 5. The location of the wall on the floor of Hanxiang Pavilion

to analyze the entire garden environment, and reasonable speculation of the original shape of the landscape can be made. We can get the most direct and accurate restoration basis through surveying and mapping of the site status, but we still need to combine relevant archives and literature to conduct textual research on the severely damaged part and elevation scale.

\subsection{Construction archives}

The restoration research of Chinese classical gardens benefits from the good literature tradition of ancient China. In the case of Qiwang Hall, we can draw important evidence from the following literature and archives.

Different from other sites (Wang, 2017), the Summer Palace and other royal gardens in the Qing Dynasty have left a lot of archives information in the process of construction and historical changes. This provides an abundant material basis for the subsequent restoration research work.

\subsubsection{Yangshi Lei Chart:}

The Yangshi Lei Chart is the architectural drawings, models, engineering practices and documents made by the Qing dynasty architect Lei family when they participated in the design process of royal architecture. It covers the survey site map, architectural design sketch, final drawing, construction process map, etc. There are currently 7 pieces of Yangshi Lei Chart related to Qiwang Hall Garden that have been survived. Six of them are the survey map of Qingyi Garden. One of them is the survey map of Qiwang Hall.

There is no record of size information in the survey maps of the Qingyi Garden, which show the plane form of the building and the overall pattern of the Qiwang Hall Garden (Figure 6a). The survey map of Qiwang Hall has recorded its door position and its bay, depth, column height, stylobate height and other size information (Figure 6b). Both flat and dimensional data are important evidence for subsequent recovery designs.

\subsubsection{Furnishing archives:}

In order to facilitate the management of the interior furnishings of the royal building, the Imperial Household Department records the interior decoration and furniture. Some of these furnishings archives directly record the type and number of furnishings, which are of little value to the study of architecture restoration. There are also some furnishing archives that first describe the spatial location and then list the specific furnishings and explain it. This type of record combines the furnishings and decorations with the architectural space, which is the basis for the inference of architectural interior space. There are five existing archives on the furnishings of the Qiwang Hall Garden in 1807, 1836, 1844, 1859 and 1863.These furnishings archives have no conflicts in the content records, and the contents of furnishing archive in 1807 are the most detailed. By studying the spatial location and furnishings recorded in the furnishing archives, we can get the partition information of the building. Meanwhile, the number of floors can also be inferred by the furnishing archives. For example, the furnishing archive in 1807 of the Qiwang Hall Garden contained three buildings with furnishings, none of which mentioned the second floor. Therefore, it can be inferred that these three buildings are single-story buildings.
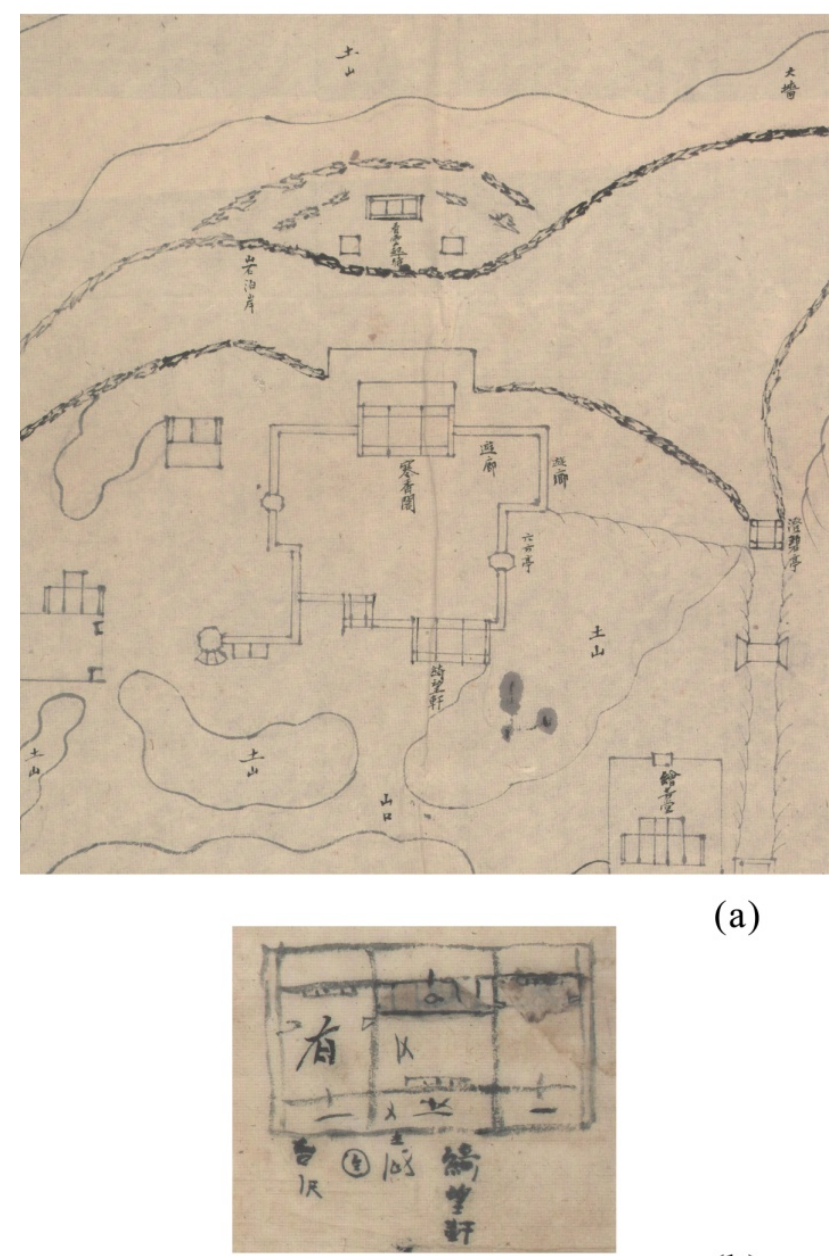

(a)

Figure 6. The survey map of Qiwang Hall Garden from theYangshi Lei Chart (National Library of China, 2018)

\subsubsection{Survey archives:}

In 1873, Emperor Tongzhi sent someone to survey and record the extant rooms of Qingyi Garden, Jingming Garden and Jingyi Garden in order to solve the problem of wood used for the reconstruction of the Old Summer Palace (Zhang, 2013a). In this archive, the size information of the two buildings in the Qiwang Hall Garden is recorded.

The record said that there are three bays in Qiwang Hall. The width of it is one zhang ${ }^{1}$ and four chi ${ }^{2}$. The depth of it is one zhang and the height of its column is one zhang and five cun ${ }^{3}$.

\footnotetext{
${ }^{1}$ Zhang is a unit in Chinese lineal measurement slightly longer than ten feet.

${ }^{2}$ Chi is one-tenth of zhang in Chinese lineal measurement.

${ }^{3}$ Cun is one-tenth of Chi in Chinese lineal measurement.
} 
Hanxiang Pavilion has three bays with the width of one zhang and four chi. The depth of it is one zhang and one chi. The height of its column is one zhang. This archive provides us with important building height information.

\subsection{Literature}

\section{Emperor Qianlong's poems:}

The Qiwang Hall Garden was an important transportation node during the visit of Emperor Qianlong to the Summer Palace. During the decades, he visited Qiwang Hall Garden many times and left 26 poems describing it. Although this literature cannot directly and accurately reflect the size data or shape and structure information of gardens, they contain some spatial environment image information, which can be used as evidence in the restoration research process.

For example, in these poems, there are twenty poems describing Cuilai pavilion in the Qiwang Hall Garden, from which we can see the relationship between garden plants and architecture, as well as the design intention at that time. “乔柏从中一小亭, 隔 窗籁想翠泠泠” describes a pavilion surrounded by cypress trees. The author heard the sound of the cypress leaves through the window and thought of its green color. “山右亩平处, 潇然 翠籁亭. 防楹弗宇廓，四面有窗棂” describes a quiet pavilion on the west side of the mountain. The pavilion is not large, with windows on all sides. The environmental information such as the cypresses and windows mentioned in these poems provide an auxiliary basis for us to restore the façade image of Cuilai Pavilion in Qiwang Hall Garden.

\section{METHOD}

\subsection{D- terrestrial laser scanning}

TSL scanning has been used in the field of heritage mapping for many years, greatly improving the efficiency of the operation. Compared with traditional measurement methods, 3D laser scanning improves the accuracy and achieves uniform precision, avoiding error accumulation during measurement. Scanning surveying and mapping of irregular objects can solve the problem that traditional surveying and mapping cannot solve, and obtain high-quality surveying and mapping results (Bai et al. 2013a). This provides the conditions for detailed mapping and recording of irregular elements in Chinese garden sites. The research group carried on the three-dimensional scanning to the Qiwang Hall Garden and the Hall for Watching Cloud Rising. The instrument used is Faro Focus 3D X130 with a maximum scanning range of $330 \mathrm{~m}$. After the scanning is completed, the supporting software is used for point cloud splicing processing. The site area to be scanned is about 13,000 square meters. The point accuracy of $3 \mathrm{~d}$ scanning depends on the error of distance and angle measurement. At the same time, as the distance from the scanner to the target increases, the error of point location determination will be affected by the error of distance measurement and Angle measurement. The current 3d scanning technology cannot achieve the mm level mapping accuracy (Bai et al. 2012a). Therefore, for some small size components, it is still necessary to combine traditional manual measurement to avoid errors. Because the size of these small components is crucial to the eventual restoration of the garden building. After the previous information collection, the data information of the site is transformed into a 3D model and 2D drawings (Figure 7). In order to ensure the accuracy, for topographic information, the axis size of the building and other large sizes are obtained through the point cloud obtained by TLS. At the same time, manual measurement data is still used for small component sizes such as column foundation and paving. The point cloud obtained by TLS is used to build the model and then speculate on the original terrain and space. At the same time, the deviation of data details is controlled by combining the manual measurement of small-sized components.

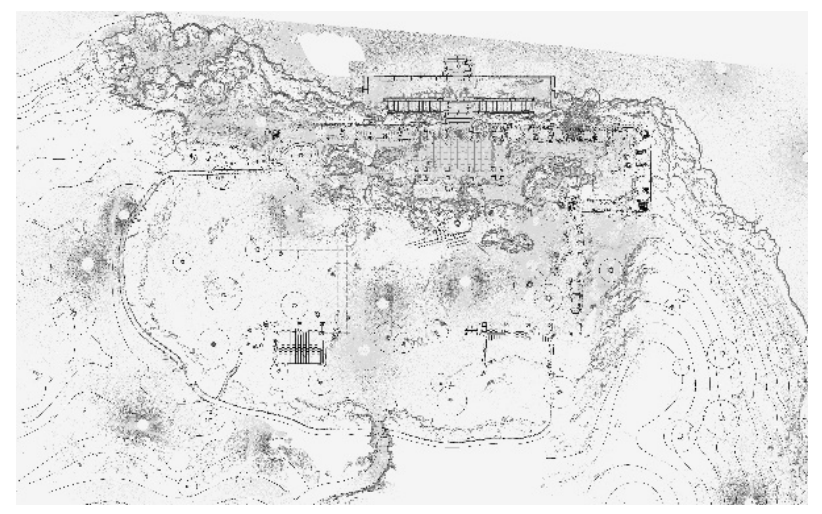

Figure 7. Current Situation Plane of Qiwang Hall Garden

\subsection{The principle of restoration design}

This restoration design is based on the site survey. Through the analysis of the field survey data, we can get the plane form and size information of most buildings in the garden. Information that cannot be reflected in the site survey is obtained through the construction archives.

For data not available in existing sites, we can look for data support by searching the construction archives. If the damage to the existing site is serious and it is impossible to judge the flat form of the building through the existing site, the plane drawn by the pattern in the archive shall prevail. These can be used as direct evidence of restoration design.

Other images of the garden are reasonably speculated based on existing mastery information.

The architect Liang sicheng sorted out and summarized the scale relationship of each component size of the royal building in the Qing dynasty (Liang, 1981). By using the proportional relation between them, we can deduce the overall image of the building from the known small amount of component size information. The details of the building's facade image can be designed by referring to the existing cases of royal gardens in the Qing dynasty.

The environment of the garden, especially the regeneration of plants, is very fast and cannot be restored very accurately by information such as on-site remains, so only reasonable speculations on the plant environment are made.

\subsection{Data processing in restoration design}

In the restoration process, we need to integrate the data obtained from field investigation and archives. However, since we used metric units in the field investigation, and what is recorded in the archives is the measurement unit of the Qing Dynasty, in order to obtain relatively accurate building size information, it is necessary to convert the dimension unit. Since the actual scale represented by Chinese units of measurement varies from time to time, we cannot directly convert them.

First, the size data obtained from the survey site is compared with the size data in the corresponding survey archives to obtain a conversion ratio between the two (Table 1). As can be seen from the table, a chi at that time was equal to 320 millimeters in metric units. Then convert the remaining data from the archives 
according to the obtained ratio. In this way, we can get relatively accurate size information from the archives.

\begin{tabular}{|c|c|c|c|}
\hline Dimension & $\begin{array}{c}\text { Site } \\
\text { survey }\end{array}$ & Archives & $\begin{array}{c}\text { Ratio } \\
\text { (archives/ } \\
\text { site survey })\end{array}$ \\
\hline $\begin{array}{c}\text { Width of } \\
\text { Hanxiang } \\
\text { Pavilion }\end{array}$ & $\begin{array}{c}1 \text { zhang } \\
\text { and } 1 \text { chi } \\
(11 \text { chi })\end{array}$ & $\begin{array}{c}3520 \\
\mathrm{~mm}\end{array}$ & $1 \mathrm{chi}=320 \mathrm{~mm}$ \\
\hline $\begin{array}{c}\text { Depth of } \\
\text { Hanxiang } \\
\text { Pavilion }\end{array}$ & $\begin{array}{c}1 \text { zhang } \\
\text { and } 4 \text { chi } \\
(14 \text { chi })\end{array}$ & $\begin{array}{c}4480 \\
\mathrm{~mm}\end{array}$ & 1 chi $=320 \mathrm{~mm}$ \\
\hline $\begin{array}{c}\text { Width of } \\
\text { Qiwang } \\
\text { Hall }\end{array}$ & $\begin{array}{c}1 \text { zhang } \\
(10 \text { chi })\end{array}$ & $\begin{array}{c}3200 \\
\mathrm{~mm}\end{array}$ & 1 chi $=320 \mathrm{~mm}$ \\
\hline $\begin{array}{c}\text { Depth of } \\
\text { Qiwang } \\
\text { Hall }\end{array}$ & $\begin{array}{c}1 \text { zhang } \\
\text { and } 4 \text { chi } \\
(14 \text { chi })\end{array}$ & $\begin{array}{c}4480 \\
\mathrm{~mm}\end{array}$ & $1 \mathrm{chi}=320 \mathrm{~mm}$ \\
\hline
\end{tabular}

Table 1. Dimensional conversion

\subsection{Method of deriving a roof style from a plane}

There are several roof forms in Chinese traditional architecture, such as overhanging gable roof and hip and gable roof, etc. After conducting a large number of investigations and restoration studies related to the Royal Garden of the Qing Dynasty, the research team found that the size of the Shanchu (the distance between the foundation of the building and the eaves column) has a certain connection with the roof. Shanchu of the flush-gable-roof building is the smallest, followed by buildings with an overhanging gable roof. The Shanchu of the gable-and-hip-roof building and the hiproof building is larger. However, in traditional Chinese architecture, the hip-roof building rarely appears in landscape architecture. According to these characteristics, we can judge the roof form of the building from the foundation left at the site. For example, it was found in the field survey that the size of the Shanchu of Hanxiang Pavilion was very large (Figure 8), so it was likely to have the gable-and-hip roof. The gable-and-hiproof buildings in Chinese garden usually adopt the form of round ridge roof. Such cases are common in other gardens of the same period, so we can conclude that the roof of Hanxiang Pavilion is the gable-and-hip roof with a round ridge.

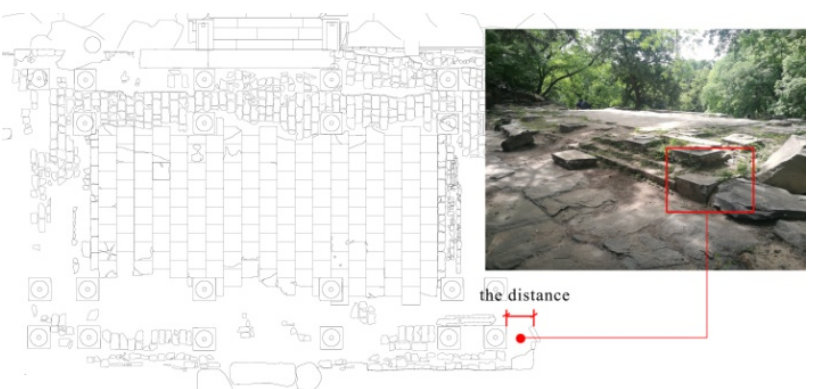

Figure 8. The Shanchu of Hanxiang Pavilion

\subsection{Method of restoration of plant landscape}

In addition to the ancient trees with clear historical records, the previous relatively common identification method of ancient trees was to measure the diameter at breast height (DBH). The ancient tree of more than 300 years is designated as the first grade, and is represented by the red card "Axxxxx". It is measured by the DBH, which varies according to the species of the tree. The cypress is $60 \mathrm{~cm}$ and the pine is $70 \mathrm{~cm}$. The ancient trees between 100 and 300 years are classified as second grades and are indicated by the green card "Bxxxxx". The cypress has a DBH of about 30 to $60 \mathrm{~cm}$ and the pine is 40 to $70 \mathrm{~cm}$. In the site survey, we found that there are a total of 13 second-grade old cypresses with green cards and one first-grade old pine with red cards in the Qiwang Hall Garden (Figure 9). There were two first-grade old cypresses with red cards in front of the Hall for Watching Cloud Rising. However, the DBH of trees is greatly affected by other factors such as climate, so the age of ancient trees cannot be accurately calculated. The error of this identification method is large, and can not determine whether these ancient trees were in the garden at that time. From Emperor Qianlong's poems, we can know that there are ancient cypress trees in the courtyard on the west side where Cuilai Pavilion is located. There is no doubt about it. But whether or not these cypress trees are what we're seeing now needs to be supported by relatively precise techniques.

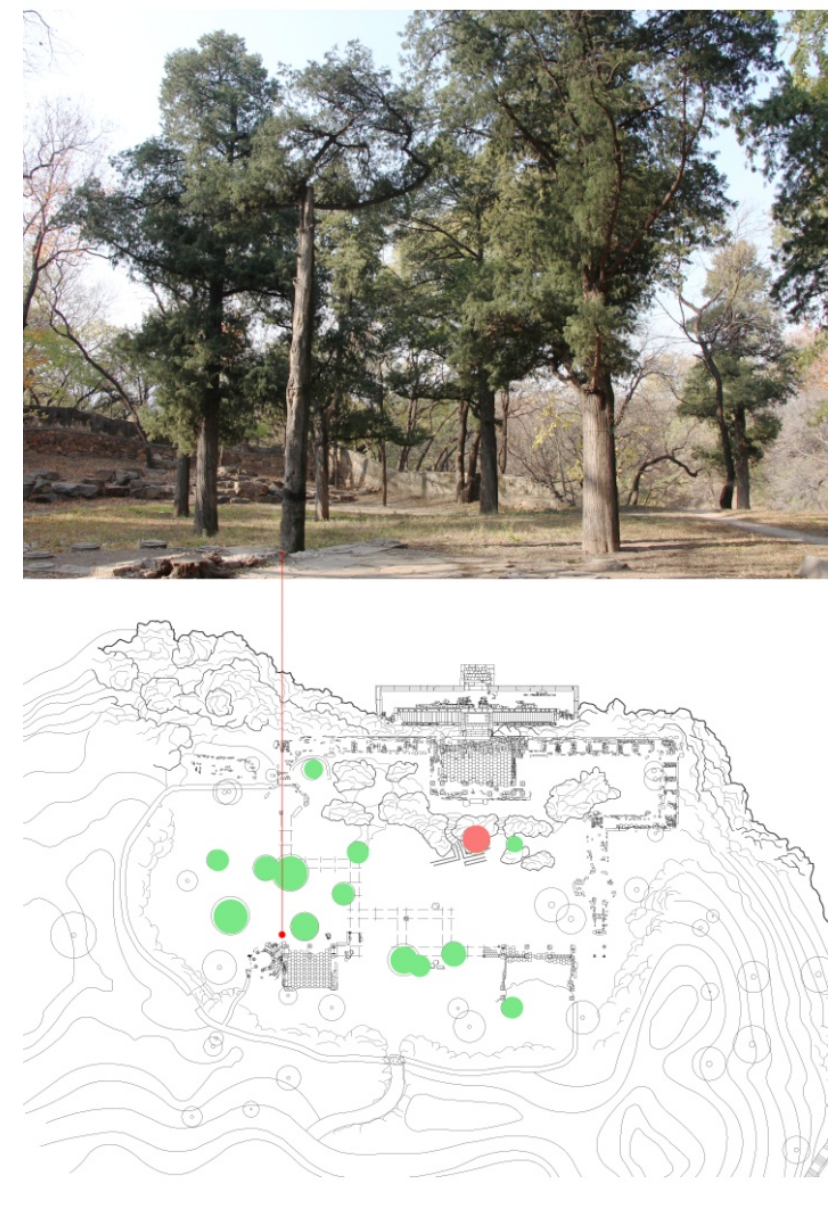

Figure 9. The old trees in the Qiwang Hall Garden

Tree ring identification method can be adopted on the premise of not affecting the growth of trees. The core of the tree to be measured is drilled with a growth cone. Dry, fix and sand the core sample. Tree rings can be interpreted by artificial or tree ring analyzer, and the tree age can be inferred according to the number of rings. In this way, we can get a relatively accurate tree age to help us judge the location of garden plants at that time. Plants are an indispensable part of a garden but compared with stacking stones in a garden, plants are alive, so it is 
difficult for us to know the exact image and location of them in those days. There is also a lack of accurate documentation of plants. In addition to the plants that we have determined once existed in this garden, for the sake of the integrity of the whole garden plant environment, other parts can only be speculated through other similar garden plant setting techniques and local common plant species.

\section{RESULT AND DISCUSSION}

Based on the above restoring materials and methods, preliminary restoring results are obtained (Figure 10). As there are no historical photographs of Qiwang Hall Garden and the Hall for Watching Cloud Rising at present, the images in the current restoration results are reasonable speculation, as an exploratory study of the original landscape. This is a relatively scientific result.

As mentioned above, the overall image of the building can be roughly deduced by referring to the architectural images of the same period and the relationship between the various components of the royal building in the Qing Dynasty when the site components such as the architectural plane are known. However, the creation of Chinese classical gardens is not all the product of stereotypes. Chinese gardens are very flexible and free, and the architecture sometimes bears the owner's own design ideas, which are different from the official practice.

For some special cases, we cannot find similar architectural forms in the same period such as the Cuilai Pavilion. Therefore, the form of the roof was speculated through architectural methods, and a form that most conforms to the artistic conception of the garden at that time was selected.

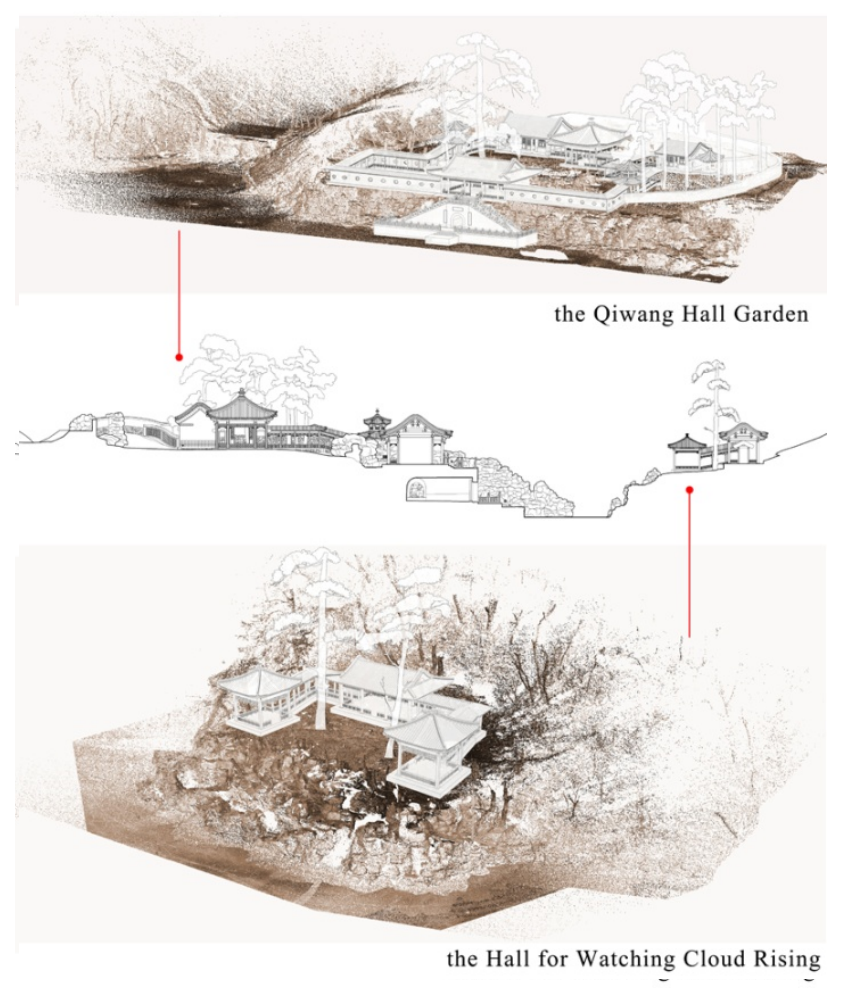

Figure 10. Landscape restoration based on TLS

\section{CONCLUSIONS}

In the process of research, it can be seen that TLS technology provides great convenience for the restoration of garden sites.
At the same time, the various measurement methods, data processing, data recording, and judgment method are not only useful for the protection and restoration research of the garden in the Royal Garden in the Qing Dynasty but also can be applied to other studies of cultural heritage sites with various elements and complex spatial characteristics.

\section{ACKNOWLEDGEMENTS}

The author would like to thank the students including Yan Jin, Chang Zhenning, Xie Jialiang, Liu Xiongwei for their help in the fieldwork of this study.

\section{REFERENCES}

Shao, J., Zhang, W., Mellado, N., Grussenmeyer, P., Li, R., Chen, Y., Wan, P. Zhang, X., Cai, S., 2019a. Automated markerless registration of point clouds from TLS and structured light scanner for heritage documentation. Journal Of Cultural Heritage.35, 16-24.

School of Architecture, Tsinghua University, 2000. The Summer Palace. China Architecture \& Building Press, Beijing, China, 132-135, 420-426.

Liang S., 1981. Qing Structural Regulations. China Architecture\& Building Press, Beijing, 87-99

Zhang L.; Zhu W.; Gu Y., 2013a. A textual research on the remaining architecture of Qingyiyuan in Xianfeng Decade . Chinese Landscape Architecture. 29(3), 120-124.

Wang, G., 2017. Lost Glory - Partly Seen in Historical Records of The Restoration of Ancient Chinese Architecture. Tsinghua University Press. Beijing, 86-118.

Jin, B.,1984a. The garden art and architecture of the back hill of the Qingyi Garden. Journal of the old Summer Palace., 3, 143-154.

National Library of China, 2018. National Library of China collected Yangshi Lei Chart - the Summer Palace volume. National Library of China Publishing House. 6, 38-40.

Bai, C., Wang, Q., 2013a. Application of 3D laser scanning technology in cultural relics and archaeological mapping. Cultural Relics., 3, 88-93.

Bai, C., Wu, C., 2012a. Research on the key problem of 3D laser scanning technology in surveying and mapping of cultural relic buildings. Bulletin of Surveying and Mapping., 1, 36-38. 